\title{
Online Training and Serious Games in Clinical Training in Nursing and Midwife Education
}

\author{
Galya Georgieva-Tsaneva ${ }^{1}$ \\ Institute of Robotics \\ Bulgarian Academy of Sciences \\ Sofia, Bulgaria
}

\author{
Ivanichka Serbezova ${ }^{2}$ \\ Faculty of Public Health and Healthcare \\ Angel Kanchev University \\ Ruse, Bulgaria
}

\begin{abstract}
The article examines the application, methods, and trends in online training of health care and medical professionals in Bulgaria. Attention is paid to modern methods for the effective application of online training and the extent to which online training can replace traditional training. The article presents the results of a survey for online training conducted in April 2021 at universities in Bulgaria Health Care professional field, specialty Nurse and Midwife. The results of the survey can serve to improve online education in Bulgaria by including in it educational resources recommended by respondents. The creation of new web-based educational resources (video materials, serious games, virtual simulations, video presentations, webinars, etc.) can complement the traditional methods of training in the students in the Health Care professional field, specialties Nurse and Midwives in Bulgaria.
\end{abstract}

Keywords-Health care; medical education; serious educational games; nurse; midwife; online training

\section{INTRODUCTION}

In today's technological age, new diverse methods of online learning are increasingly being integrated into higher health care and medical education. the questions about which are the most effective methods for online training, which technologies would be most suitable for students of the specialties Midwife and Nurse (Health Care professional field) are to be studied. Online learning of students today is influenced by the development and application of modern communication information technologies in all spheres of life, by advances in medical sciences in the detection and treatment of diseases, and by the improvement of the quality of health services.

An important issue in online learning is the implementation of learning strategies based on classical real learning, modern online learning, and practical training, which in the field of training of medical professionals can not be completely replaced by online innovation. The assessment of online learning can be made based on the degree of satisfaction of the learner (from the learning objectives and content, format, and effectiveness of learning resources), the learning outcomes (assessment of knowledge and skills of learners), improving the effectiveness of learning (improvement of practical skills) and the real health results when working with patients (changes in the behavior of patients and improvement of their health indicators as a result of the practical skills of the learners).

Online learning $[1,2]$ is learning mediated by the World Wide Web, intranet, and multimedia computer applications.
Central to online learning is the online learning resources used by students: illustrations, videos, medical images, virtual patients, and others. Medical and health care universities are looking for effective approaches to optimize online learning, which will become more widespread.

The purpose of this report is to give an idea of the online training of health care students in the academic year 2019/2020 and 2020/2021 (until April 2021) in higher universities in Bulgaria, professional field of Health Care, specialty Midwives, and Nurse. The results shown were obtained by conducting an online survey of students in these specialties at the following medical universities: Varna, Plovdiv, Sofia, Pleven, Stara Zagora in Bulgaria; University "Angel Kanchev" in Ruse, Southwestern University "Neofit Rilski" Blagoevgrad, Burgas University "Asen Zlatarov" (these three universities are not medical, but are accredited to teach in Health Care professional field).

The results of the study provide an opportunity for practical planning of future online training of health care students at universities. The differences between the theoretical views on online learning and its practical results can be correctly assessed by surveying the opinions of the students involved in online learning.

The rest of the paper is summarized as follows: Literature survey is shown in Section II. The use of serious games in medical and health care education is presented in Section III. The survey results are shown in Section IV. The conclusion is presented in Section V.

\section{TRENDS IN THE ENTRY OF ONLINE TRAINING IN MEDICAL EDUCATION}

Online medical and health care education uses the advances of information and communication technologies to transmit knowledge at a distance. In the field of medicine, teaching and acquiring practical professional skills and habits cannot be completely replaced by online learning. It can be used as complementary training, such as a lecture or demonstration complemented by an online lesson. The use of serious games in the form of quizzes for testing students' progress, the use of serious simulation games in order to consolidate theoretical knowledge and improve students' practical skills through training of real manipulations in an artificial environment is applicable. Digitized learning resources, digital libraries, and databases with learning resources are available on the web. 
In Bulgaria from March 2020 to April 2021 (when the survey was conducted), in connection with the emerging epidemiological situation, much has been done to enter and improve the quality of online education in health care education. Online learning is integrated into the curricula and a blended learning strategy is created. Many digital repositories of e-learning materials are being set up around the world, some of which are peer-reviewed, where instructors or developers can submit materials for widespread use.

Study [3] of the Liaison Committee on Medical Education in the U.S. shows an increase in the use of educational software products in medical education, as well as an increase in the number of websites that use integrated online learning. There is an increase in the effectiveness of training [4] using web-based knowledge and an increase in consumer satisfaction with online learning.

Initiatives are being created [1] to create a digital repository for peer-reviewed electronic resources for public distribution.

It is proposed to create a mechanism for sharing quality resources for online learning between individual educational institutions and stimulating the work of teachers through peer review processes. Providing learning materials in various formats - using video, audio, other technologies, or software in the form of serious educational games [5] - these are tools that can make learning more interesting and also allow students to improve the quality of their learning.

As a professional, the health care and medical specialist must contribute to [6]:

- promoting healthy habits;

- carrying out disease prevention;

- treatment of patients;

- to work for the rehabilitation of the recovered patients;

- to conduct a constant process of learning everything new.

The main principles of medical and health care education are the acquisition of education leading to the first professional degree; clinical education, which is preparation for a general medical and health care practice or specialty and obligatory continuous, lifelong training of every higher specialist. According to [7] continuing medical education is a very important requirement for the development of medical professionals.

Internet technologies enable the distribution and use of digital content among many users simultaneously at any time and from anywhere in the world. For employed medical professionals [8], the ability to learn when they can or need information is highly desirable. The educational needs in the field of medicine are diverse: providing easy, fast, and timely access to textual content or photos; inclusion of serious games in the form of virtual reality systems, virtual learning techniques, and virtual patient care in health care and medical education.
Research reported in $[9,10]$ shows that effective learning can be achieved by combining traditional learning with distance learning.

There is a continuous growth in knowledge of the structure and function of the human body. In many areas of application, there is a simultaneous rapid growth of various innovative methods. Today, many factors in higher education make teaching and learning difficult. This includes a shorter hospital stay for critically ill patients and limited time for medical professionals to work with each patient. There is a shift from traditional practical medical actions to computer-based manipulations or images due to the modernization of technology.

According to [11] free access to medical education sites, online medical journals, textbooks, and the latest information on medical innovation, the use of serious games also encourages learning and research.

The development of clinical informatics [12] aims to improve patient care through the use of modern technologies and increase the efficiency of both patient care and safety.

E-learning began to be used about 20 years ago. From then until today, it has undergone significant development - from its original idea to the modern experience in an electronic or webbased application. E-learning enters all stages of education and then continues in the form of lifelong learning. At the beginning of the creation of the web, e-learning included a virtual learning environment (Virtual Learning Environment), expensive software, work plan, and tested. At this earlier stage of development, e-learning is oriented to the interests and goals of the educational institution.

The development of e-learning in the coming years is already oriented to the needs of the learners themselves, who become active participants in this bilateral process. Learners share ideas, offer solutions to problems, collectively use different sources, and can participate in the creation of new knowledge. In this way a learning community is already created, the aim is to support the interaction not only between the teacher and the students but also between the students themselves. According to [13] upgrading on the already acquired knowledge of the learners, stimulating creativity, creative thinking, spontaneous reaction, and working on breaking the traditional education by introducing an element of fun. The role of the teacher and the trainer is expanded and enriched, the qualitative characteristics of the education are put in the foreground, new methods for increasing the motivation of the students are sought.

The study, conducted in [14], aims to examine the extent to which online resources are used by medical graduates and ways to increase interest in them. The authors point out as a conclusion the need to integrate information technology into traditional education, change the curriculum, transition to structured computer training of medical students.

\section{Serious GAmes AS A Method FOR EFFective LEARNING}

Computer games, which, unlike games created for entertainment, serve to achieve certain useful goals, supporting 
the formation of professional knowledge, skills, and competencies, and are called serious games [15, 16]. Serious educational games differ from entertainment games mainly in the presence of pre-set pedagogical goals. According to [17], the serious game is "an interactive computer application, with or without a significant hardware component, that has a challenging goal, is fun to play with, incorporates some concept of scoring, and imparts in the user a skill, knowledge or attitude which can be applied in the real world”. Serious games are gradually becoming a popular modern development [18], due to the support they provide to educational processes, attracting and retaining attention to the learning material and provoking useful behavior in students. Along with the acquisition of knowledge, learners develop problem-solving skills, cooperation, communication, and interaction in a competitive environment, lead to improved creativity and strengthen their participation in the learning process.

Traditional lecture-based teaching [19] emphasizes the transmission of information and the use of memory to achieve educational effects. Serious learning games are attractive to their users because they are not based on the traditional teaching methods that are boring for learners today. Traditional learning is increasingly perceived by learners as ineffective and cannot hold their attention. The games confront students with a problem that engages their attention and interest and offer possible ways to explore the problem situation. In this way, students have the opportunity to upgrade their knowledge. Game design elements are designed to attract students' attention [20] and challenge them to solve problems.

Looking to the near future we can note the implementation of Gamification in education, which can be defined as a learning platform [21] that aims to give additional motivation to learners, provide feedback and use as incentive rewards (points, badges, boards for leaders, progress lanes, etc.). In gamification [22], the whole learning process becomes a game in order to motivate and interact students through game mechanics and game elements. Unlike gamification, gamebased learning uses games only as part of the learning process. To the goals of gamification can be added the achievement of an attractive learning process, provided by performing fun activities, gaining a modern learning experience.

The authors of [19] in 2019 conducted a study of the use and impact of serious games scientific education, using mixed qualitative and quantitative data. The opinions of students and parents about the influence of serious educational games were studied. The obtained results show positive results on the motivation of students in the learning process.

Today, web technologies are influential factors in students' lives and learning. Interaction in online and offline media, which offer a modern educational environment, creates significant changes in students [23]. Online educational platforms play a key role in changing students' values, beliefs and behavior.

Modernization of technologies leads to mandatory integration of technology with education and educational systems need to be constantly changed and improved. This leads [24] to the emergence of new approaches to learning and teaching.
According to [25], any serious game must have the following characteristics: a method of communication between the person and the game; assessment by the number of correct answers; conflict (challenge); the ability of users to change the game (controllability); environment; history or fiction; interaction between users; immersion in the game; rules and goals of the game provided to the user.

In the training of health care and medical professionals, it is essential that students be able to enhance their practical skills through the use of games involving virtual simulations of real activities [26] performed on patients. Thus, the trial and error method has no negative consequences on the patients themselves.

Despite the entry of serious games into training [27], game developers do not pay enough attention to validating the effect of using serious games.

Works [28, 29] examined the barriers in web space and the accessibility of serious training games for students with visual impairments.

\section{RESUlts OF THE StUdy ON THE ONLINE TRAINING AND SERIOUS GAMES IN CLINICAL TRAINING}

A survey on the issues of online training education and serious games in clinical training in Bulgaria was conducted in April 2021 with students learning in the specialties nurses and midwives at health care and medical Universities in Bulgaria. Teachers' and students' views on virtual methods were surveyed using a survey created using the Google Forms application. The survey includes 486 respondents, health care students in Bulgaria. The online survey was conducted on a voluntary and anonymous basis. The survey was conducted among respondents from the Faculties of Public Health and Health Care of Universities in the Republic of Bulgaria, that train specialists in the professional field of Health Care, such as Ruse University “Angel Kanchev”, Southwestern University "Neofit Rilski" - Blagoevgrad, Burgas University "Asen Zlatarov”, Varna Medical University (and its branches in the country), Universities in Plovdiv, Sofia, Pleven, Stara Zagora. The questions in the survey are 15 in number.

Table I presents the characteristics of the respondents according to their training course. The survey was conducted among students who in April 2021 are studying in the 1st, 2nd, 3rd, and 4th year at higher universities in Bulgaria. The 1st and 3rd year students were the most active in filling in the questionnaire.

Regarding the degree of satisfaction of students with the online training conducted in the academic year 2019/2020 and 2020/2021, 51.4\% believe that they like online training completely. $24.3 \%$ think that they are not satisfied enough and expected more, and 22.2\% cannot give a clear assessment. According to other students who indicated an open answer, online learning cannot replace face-to-face learning $(0.8 \%)$, $0.6 \%$ say they are satisfied with online learning but prefer to learn face-to-face. Several students point out the importance of attending the internship and exercises during the online training. Overall, 67.5\% (238) of the students indicated that they preferred the present form of education to online learning. 
TABLE I. COURSE OF TRAINING

\begin{tabular}{|l|l|l|l|l|}
\hline Course & $\mathbf{1}$ & $\mathbf{2}$ & $\mathbf{3}$ & $\mathbf{4}$ \\
\hline $\begin{array}{l}\text { \% (Number of } \\
\text { participants) }\end{array}$ & $\begin{array}{l}32,9 \% \\
(160)\end{array}$ & $23 \%(112)$ & $\begin{array}{l}32,5 \% \\
(158)\end{array}$ & $\begin{array}{l}11,5 \% \\
(56)\end{array}$ \\
\hline
\end{tabular}

The study of what students liked the most in online learning is presented in Fig. 1. The question allows you to choose several answers. According to 294 (60.5\%) respondents, the biggest advantage of online learning is the created opportunity for Accessibility to learning materials (platforms, online resources, presentations, video materials, etc.). This shows the desire of students to use web educational resources. This opportunity can be for them provided and through real training and lead to an increase in its quality. The opportunity to learn from home is essential for 246 participants, which is more than half of the surveyed students. Respondents point to the advantages of greater independence and flexibility in learning and the ability to use modern technologies.

The study on the shortcomings of online learning according to students is presented in Fig. 2. The question allows you to choose several answers. According to the respondents, the biggest shortcomings are: the lack of direct contact with their teachers (according to 61.7\%); the lack of a real hospital environment in which to learn skills for manipulations (according to 56.8\%); in training in higher health care specialties, real training is necessary and very important (according to 53.5\%); the lack of daily direct contact with fellow students is essential for $51 \%$ of respondents.

Fig. 3 shows the degree of response of the respective university in its transition to online learning. According to $48.6 \%$ of the respondents, their university immediately switched to online education, while $44 \%$ of the students stated that the transition was gradual. $7 \%$ of students say that in their higher university there was a distance form of education even before the pandemic.

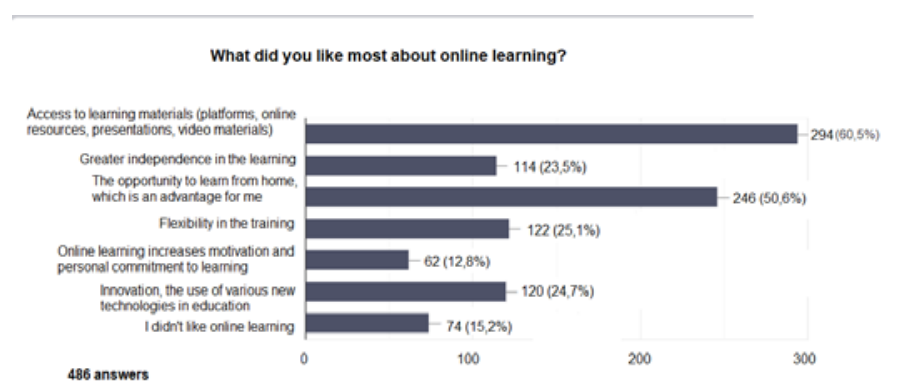

Fig. 1. Exploring the Benefits of Online Learning.

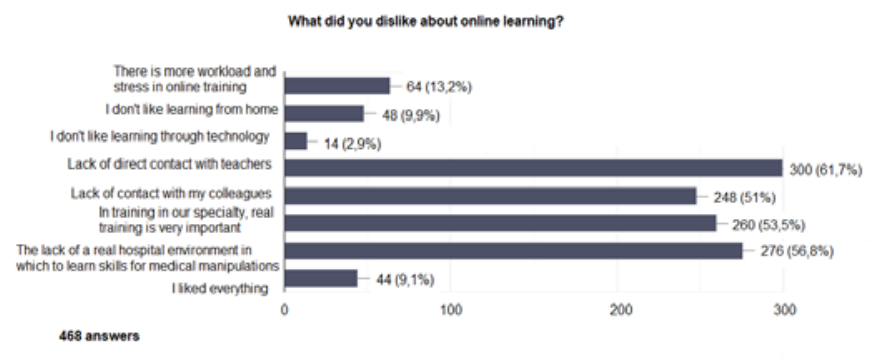

Fig. 2. The Studying the Shortcomings of Online Learning.
How did your university move to online learning?

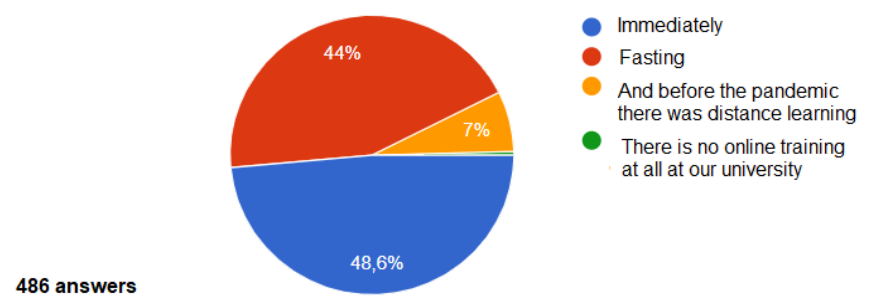

Fig. 3. Studying the Speed of the Transition to Online Learning.

Fig. 4 presents the means of communication through which students connected with their teachers during online learning. According to respondents, the most commonly used means of exchanging information is e-mail (63\%), followed by Google Classroom (37\%), Viber (74\%), and Phone (35.8\%).

Fig. 5 shows the degree to which students coped during the online training in mastering the material and practical health care manipulations. $41.6 \%$ of the respondents state that they have not encountered problems with online learning, 36.6\% declared that they had difficulties at the beginning of online training, which they then coped with, according to $11.1 \%$ of students online learning creates difficulties in mastering the health care procedures that require real clinical practice.

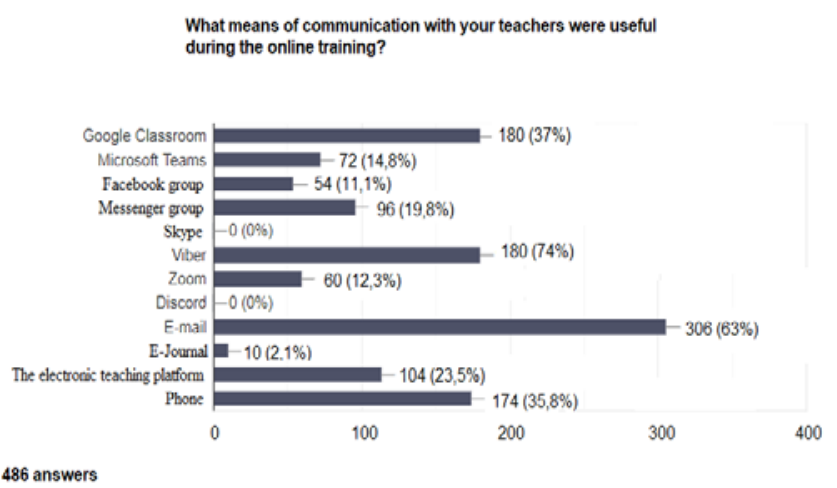

Fig. 4. Means of Communication.

To what extent do you think you have dealt with tasks?

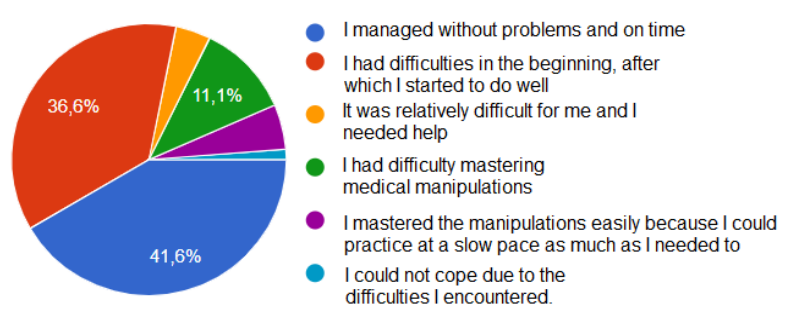

486 answers

Fig. 5. Degree of Coping in Online Learning. 
Fig. 6 presents the useful learning tools that can be used in future online learning according to the respondents. The largest part $(68.7 \%)$ of the surveyed students believe that the video materials on the respective medical disciplines will be of great help to them in the online training. According to $56.4 \%$ of the respondents, video presentations prepared on the lecture material will be of great benefit in their training. $44.4 \%$ of the respondents indicate the websites with educational resources uploaded on them as a useful tool in mastering the study material. $24.28 \%$ of respondents point to serious games as a modern learning tool.

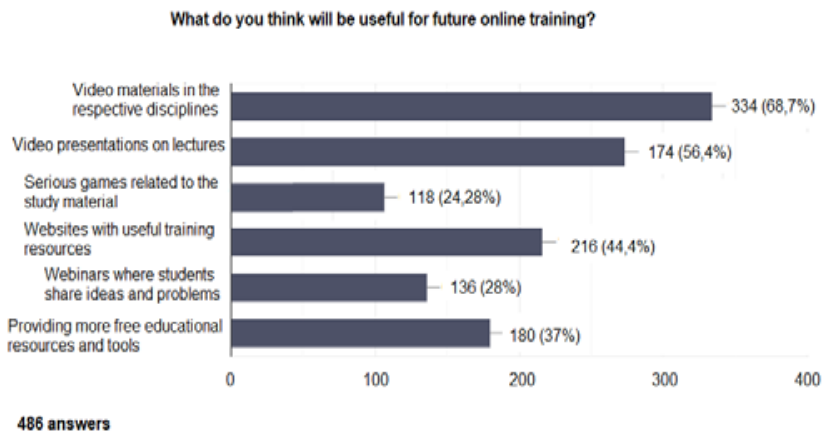

Fig. 6. Useful Tools for Future Online Training.

Regarding the device with which they conducted their training, 65\% (316 participants) indicated a telephone, 90.1\% (438 participants) used a laptop, 9.9\% (48 participants) used a computer, 9.1\% (44 participants) used a tablet. The questionnaire allows you to choose more than 1 answer to this question.

According to the survey, $17.3 \%$ of students report that they have had problems with the Internet connection, 63\% believe that sometimes the connection has been interrupted, and 19.8\% of the respondents, the connection has always been good.

\section{CONCLUSION}

In today's technological society, the inclusion of innovative interactive digital tools in the process of training in medical specialties is imperative and undoubtedly contributes to improving the quality of teaching. In periods requiring online learning as the only method, it is necessary to use the Internet effectively with all its advantages: access to digitized online learning resources, creation and use of appropriate videos, presentations, webinars, serious educational games, video simulations, and much more.

The results of the survey conducted among students trained in specialties Midwife and Nurse show that higher universities in Bulgaria have done well in the periods of compulsory online training in 2020 and 2021 (until April, when the survey was conducted) and have offered effective, quality training to their students.

The results of the survey can be a tool for assessing and improving the quality of online learning and serve as a corrective in the next periods of online learning in higher universities in Bulgaria.
Future plans and recommendations for the future development of the education of health care and medical students. One of the most important conclusions made as a result of the research is that the real education of health care students cannot be replaced by sufficient quality online education. This shows that the training program for health care students must be carefully considered and include all opportunities for real involvement of students in clinical practice, where they can gain real experience in working with patients.

The results of the study also indicate the positive aspects of the introduction of technology in the education of Health Care students and the application of online learning. The creation of new web-based educational resources (video materials, serious games, virtual simulations, video presentations, webinars, etc.) can complement traditional teaching methods and make higher education in medicine in Bulgaria high quality, modern, effective and attractive for future health care and medical professionals.

\section{ACKNOWLEDGMENT}

This work was supported by the Bulgarian Ministry of Education and Science under the National Research Programme "Young scientists and postdoctoral students" approved by DCM \# 577/17.08.2018.

\section{REFERENCES}

[1] T. Anastasiadis, G. Lampropoulos, K. V. Siakas. "Digital Game-based Learning and Serious Games in Education”. International Journal of Advances in Scientific Research and Engineering, Vol. 4, Iss. 12, 2018, pp. 139-144, DOI: 10.31695/IJASRE.2018.33016.

[2] N. Hamzah, A. Ariffin, H. Hamid. "Web-Based Learning Environment Based on Students' Needs”. International Research and Innovation Summit (IRIS2017) IOP Publishing, IOP Conf. Series: Materials Science and Engineering 226, 2017, 012196, doi:10.1088/1757899X/226/1/012196.

[3] M. Al-Balas, H. I. Al-Balas, H. M. Jaber, K. Obeidat, H. Al-Balas, E.A. Aborajooh, R. Al-Taher, and B. Al-Balas, "Distance learning in clinical medical education amid COVID-19 pandemic in Jordan: current situation, challenges, and perspectives. BMC Medical Education, 2020, 20:341, https://doi.org/10.1186/s12909-020-02257-4.

[4] K. Soussi, "Web-based Learning: Characteristics, Practices, Challenges and Recommendations”. International Journal of Science and Research, 2020, 9(3), pp. 936-943, DOI: 10.21275/SR20312135240.

[5] G. Georgieva-Tsaneva, "Serious Games and Innovative Technologies in Medical Education in Bulgaria”. TEM Journal. Vol. 8, Iss. 4, pp. 13981403, ISSN 2217-8309, DOI: 10.18421/TEM84-42, 2019, pp. 13981403.

[6] A. Ghanizadeh, S. Mosallaei, M. S. Dorche, A. Sahraian, P. Yazdanshenas. „Use of E-learning in education: attitude of medical students of shiraz“, Iran. Int Med Medical Investigation J. 2018, 3(3), pp.108-11.

[7] M. Steinman, S. Landefeld, R. Baron, "Industry Support of CME - Are We at the Tipping Point?” The New England Journal of Medicine, 2012, vol. 366, pp. 1069-1071.

[8] D. Pullen, "Doctors online: Learning using an internet based content management system. International Journal of Education and Development using Information and Communication Technology", 2013, Vol. 9, Iss. 1, pp. 50-63.

[9] I. Gorbanev, S. Agudelo-Londoño, R.A. González, A. Cortes, A. Pomares, V. Delgadillo, et al. "A systematic review of serious games in medical education: quality of evidence and pedagogical strategy”. Med Educ Online, 2018, 23(1):1438718, doi: 10.1080/10872981.2018.1438718. 
[10] H. Banda, R. Franco, D. Simpson, K. Brennan, J. McKanry, \& D. Bragg, "Assessing the learning outcomes and cost effectiveness of an online sleep curriculum for medical students”. Journal of Clinical Sleep Medicine, 2012, vol. 8, No. 4, pp. 439-443.

[11] M. Azeem. „Ten ways to improve information technology in the NHS“. BMJ. 2003 Jan 25; 326(7382): 202-206.

[12] S.V. Gentry, A. Gauthier, B.L. Ehrstrom, D. Wortley, A. Lilienthal, L.T. Car, et al. „Serious gaming and gamification education in health professions: Systematic review“. J Med Internet Res, 2019, Mar 28;21(3):e12994, doi: 10.2196/12994.

[13] J. Dašić, P. Dašić, V. Šerifi, “Evolution of E-Learning”. 7th International Conference ICQME 2012. 19th-21st Sept. 2012, Tivat. pp. 311-316.

[14] P. Kasat, S. Gupta, R. Jadhav, G. Muthiyan, "The Study of Usage of Online Learning Resources in Medical Courses”. International Journal of Research in Electronics and Computer Engineering Vol. 6 (1). 2018. Pp. 1-6.

[15] D. Paneva-Marinova, M. Rousseva, M. Dimova, L. Pavlova. "Tell the Story of Ancient Thracians through Serious Game”. Ioannides M. et al. (eds) Digital Heritage. Progress in Cultural Heritage: Documentation, Preservation, and Protection. EuroMed 2018. October 29th - November 3rd, 2018. Cyprus, 11196 LNCS, Lecture Notes in Computer Science (including subseries Lecture Notes in Artificial Intelligence and Lecture Notes in Bioinformatics), 509-517, https://doi.org/10.1007/978-3-03001762-0_44.

[16] M. Dimova, D. Paneva-Marinova, L. Pavlova. “Towards Better Understanding of Ancient Civilizations by Storytelling and Gaming”. TEM Journal, 2018, 7 (3), UIKTEN - Association for Information Communication Technology Education and Science, Serbia, ISSN:22178309.

[17] B. Bergeron, “Appendix A: glossary In Developing serious games”. Hingham: Charles River Media; 2006. p. 398.

[18] C. Hursen and C. Bas, "Use of gamification applications in science education,” Int. J. Emerg. Technol. Learn., vol. 14, no.1, pp. 4-23, 2019.

[19] W. Bedwell, D. Pavlas, K. Heyne, et al. "Toward a taxonomy linking game attributes to learning: an empirical study”. Simul Gaming. 2012; 43(6):729-760.

[20] C.-H. Su, C.-H. Cheng, "A mobile gamification learning system for improving the learning motivation and achievements”. Journal of
Computer Assisted Learning. Vol. 31 (3), 2014, pp. 268-286. https://doi.org/10.1111/jcal.12088.

[21] F. Gokkaya, "Peer Bullying in Schools: A Cognitive Behavioral Intervention Program”. In book: Child and Adolescent Mental Health. 2017. DOI: $10.5772 / 66701$.

[22] R. Al-Azawi, F. Al-Faliti, and M. Al-Blushi, "Educational Gamification Vs. Game Based Learning: Comparative Study”. International Journal of Innovation, Management, and Technology, Vol. 7, No. 4, 2016, pp.132136.

[23] S. Nemorin, “Affective capture in digital school spaces and the modulation of student subjectivities". Emotion, Space and Society, 2017, 24, 11-18. https://doi.org/10.1016/j.emospa.2017.05.007.

[24] M. Gencer, T. Tok, \& A. Ordu, „Power Base Games That School Principles Use Scale: Its Development, Validity, and Reliability“. International Journal of Assessment Tools in Education, 2018, 5(2), 274288. DOI: 10.21449/ijate.407218.

[25] I. Gorbanev, S. Agudelo-Londoño, R. Gonzales, A. Cortes, A. Pomares V. Delgadilo, F. Vepes, and M. Óscar, “A systematic review of serious games in medical education: quality of evidence and pedagogical strategy.” Medical Education Online. 2018; 23 (1); https://doi.org/10.1080/10872981.2018.1438718.

[26] B. Spellberg, D. Harrington, S. Black, et al. "Capturing the diagnosis: an internal medicine education program to improve documentation.” Am J Med. 2013;126(8):739-743.

[27] M. Graafland, J. Schraagen, M. Schijven, "Systematic review of serious games for medical education and surgical skills training.” $\mathrm{Br} \mathrm{J}$ Surg. 2012, 99(10):1322-1330.

[28] N. Noev, G. Bogdanova, T. Todorov, N. Sabev. „Innovative approach to the presentation of cultural heritage in the game module of serious game for blinded people“. Digital Presentation and Preservation of Cultural and Scientific Heritage, 9, 213-218, 2019, ISSN 1314-4006 (Print) ISSN 2535-0366 (Online).

[29] G. Bogdanova, N. Sabev, N. Noev. „Accessibility and some educational barriers for visually impaired users“. Proc. of the 11th International Technology, Education and Development Conference, Mar 2019, doi: 10.21125/inted.2019.2333, 2019, ISBN: 978-84-09-08619-1, ISSN: 2340-1079. 